Fall 2008

\title{
Technology-Related Research in HRD Publications: An Analysis of Content and Metaperspectives from 2000 to 2006.
}

Rod P. Githens

University of Louisville, rgithens@pacific.edu

Khalil Dirani

University of Georgia

Jacqueline Gitonga

University of Illinois at Urbana-Champaign

Ya-Ting Teng

University of Illinois at Urbana-Champaign

Follow this and additional works at: https://scholarlycommons.pacific.edu/ed-facarticles

Part of the Business Administration, Management, and Operations Commons, Education Commons, and the Organization Development Commons

\section{Recommended Citation}

Githens, R. P., Dirani, K., Gitonga, J., \& Teng, Y. (2008). Technology-Related Research in HRD Publications: An Analysis of Content and Metaperspectives from 2000 to 2006.. Human Resource Development Quarterly, 19(3), 191-215. DOI: 10.1002/hrdq.1236

https://scholarlycommons.pacific.edu/ed-facarticles/102 


\title{
Technology-related Research in HRD Publications: An Analysis of Content and Metaperspectives from 2000 to 2006
}

\author{
Rod P. Githens \\ University of Louisville \\ Khalil Dirani \\ University of Georgia \\ Jacqueline W. Gitonga \\ University of Illinois at Urbana-Champaign \\ Ya-Ting Teng ${ }^{1}$ \\ University of Illinois at Urbana-Champaign
}

An edited version of this paper was published as:

Githens, R. P., Dirani, K., Gitonga, J. W., \& Teng, Y. T. (2008). Technology-related research in HRD publications: An analysis of content and metaperspectives from 2000 to 2006. Human Resource Development Quarterly, 19(3), pp. 191-215.

\begin{abstract}
This study explores the presence of technology-related research in HRD, identifies what the research addressed, and analyzes how the research was addressed. 1675 papers in five HRD publications were reviewed. During the seven-year period examined, 169 articles were technology-related. Through a content analysis, we identified the topics of those articles, methodological approaches, organizational settings represented in the research, the fields of the researchers, and the papers' orientation toward research and practice. In comparison to the total articles in each publication, the highest percentage of technology research was published in the conference proceedings. Of those articles, a large percentage focused on educational technology in higher education settings, while non-profit organizations and government/military settings were underrepresented. Overall, non-training topics were underrepresented. In considering the orientation toward research and practice, the systems metaperspective was most highly represented, followed by psychological, language, and community/societal metaperspectives.
\end{abstract}

Information technology (IT) has grown exponentially during the past two decades, leading to changes in nearly every field of practice. In particular, successful professionals in human resource development (HRD) have utilized IT in training and non-training interventions (Conn \& Gitonga, 2004). For instance, IT tools such as databases, collaboration systems, blogs, wikis, and instant messaging used for performance improvement and organization development have been used in non-training interventions (Benson, Johnson, \& Kuchinke, 2002). Technology in formal training programs has also been increasingly emphasized, as reported in three

\footnotetext{
${ }^{1}$ With the exception of the first author, the other three authors are listed in alphabetical order to reflect equal contributions to the work of this article. We also thank Dr. Angela Benson for her feedback and guidance in the earlier stages of this project.
} 
American Society for Training and Development (ASTD) studies (Sugrue \& Rivera, 2005) ${ }^{2}$. Among the organizations participating in these studies, $27 \%$ to $38 \%$ of all formal training was provided via technology.

While the importance of technology continues to grow in HRD, several shortcomings have been raised regarding existing technology-related research. First, technology research has focused on narrow variables and fails to reflect the real-life demands of organizations (Alavi \& Carlson, 1992; Goles \& Hirschheim, 2000). In this vein, scholars need to consider whether technology research agendas are adequately reflecting the realities of HRD practice. Secondly, approaches to technology have overemphasized how to use specific tools at the expense of any discussion of technology's larger impact on organizations or the larger society (Reffell \& Whitworth, 2002). According to Nardi and O’Day (1999), technology use does not occur in an isolated manner; instead, local technologies exist within larger "ecologies" and affect these macro systems. In HRD, we use technologies that not only impact individuals, groups, and organizations, but also larger communities and societies. With technology's increasing influence in HRD, a quantitative and qualitative examination of technology-related studies in HRD publications becomes a worthwhile endeavor. In this study, we explore (a) how much technology is being addressed in HRD research, (b) what topics are being addressed, (c) who is researching it, (d) what methods are used, (e) where it is being researched, and (f) what orientation toward research and practice is taken in the research. In this study, "technology" refers to the broad realm of information technology, which is defined as the "study, design, development, implementation, support or management" of computers, information systems, the Internet, and related digital communication technology (Information Technology Association of America, n.d., p. 30).

\section{Review of Literature}

Beyond taking an inventory of technology research in HRD, we sought to assess the qualitative differences in the research pursued in HRD. Since technology plays such a major role in the actual practice of this field, it is important that HRD technology research represent diverse viewpoints. Research in HRD has focused on limited constructs and variables, while failing to consider relevant societal issues, marginalized perspectives, and the complicated realities of HRD practice (Gedro, 2007; Jacobs, 2006; Kuchinke, 2004; Smith, 2006; Tyler, 2006). In reviewing relevant literature, we sought to understand how we might analyze technology-related HRD research in a way that determines the broadness (or lack thereof) represented in these studies.

\section{Research on Research}

In examining research within a specific field, several approaches can be taken. Conn and Gitonga (2004) conducted a study that examined the presence of workplace training and performance articles in the journals of an educational technology organization, the Association for Educational Communications and Technology (AECT). Their most notable finding was the lack of empirical research in those journals from the field of workplace learning and performance. In HRD, a frequently cited study is Bierema and Cseh's (2003) feminist analysis of papers presented at the Academy of Human Resource Development (AHRD) conferences. They found very little concern in AHRD literature for issues of gender, power, or social justice. Other

\footnotetext{
${ }^{2}$ Three original research studies were reported in the same report.
} 
studies have focused on methodology in HRD publications (Rocco et al., 2005), general content of HRD journal articles (Freeman et al., 2006), and orientations toward methodology and HRD practice (Wasti, Poell, \& Cakar, in press).

Within the field of nformation systems (IS), a lively debate has occurred over paradigms of research represented in published works. Orlikowski and Baroudi's (1991) classic analysis of IS literature found a diversity of topics represented in the field, but an overwhelming dominance by studies taking a positivist perspective (96.8\%). Only a handful of studies took an interpretive perspective and none used a critical perspective. Walsham (1995) found that "mainstream" IS journals in the U.S. were less open to interpretive research (both in their official rhetoric and in actual practice) than were an "alternative” U.S. journal and three U.K.-based journals. Each of these studies sought to analyze published research in HRD or technology studies and have generally focused on methodology, research paradigms, or topics presented. No research has analyzed the perspectives toward research and practice taken in HRD technology studies. Lastly, to our knowledge, no other research has analyzed the content of technology research within the HRD field.

\section{Research Paradigms}

The debate over positivism, interpretivism, and various critical perspectives has occurred for nearly 30 years in applied social fields like education and organization studies (e.g., Bredo \& Feinberg, 1982; Burrell \& Morgan, 1979). In recent years, this debate has found its way into HRD, especially as unconventional approaches to HRD research and practice, such as critical HRD, have gained increasing attention (Fenwick, 2004, 2005; Githens, 2007; Storberg-Walker, 2007; Valentin, 2006). Burrell and Morgan's four paradigms of research in organizations are commonly used for understanding paradigms of research and practice. Their 2x2 diagram for viewing research is based on (a) the degree to which organizations are viewed as tending toward order or chaos and (b) the degree to which social science is seen as subjective or objective. They classified research as functionalist (positivist), interpretivist, radical humanist, or radical structuralist. Although the model's elegance is powerful, Burrell and Morgan have been criticized for their view that research must fall into one of these four distinct camps rather than acknowledging that research can use multiple perspectives (Goles \& Hirschheim, 2000).

In their discussion of the IS literature, Goles and Hirschheim (2000) advocate pragmatic approaches as a middle ground in order to end the paradigm wars in the field (i.e., positivism versus interpretivism versus critical perspectives). Pragmatism focuses on "what works" and is "useful" ("usefulness" is infused with value and distinct from utilitarianism which removes questions of value). They classify pragmatists as taking a middle ground approach regarding reality, empirical evidence, and objectivity. Pragmatists focus on the research question and seek to find the best way to answer the question, while considering one's philosophical influences. Through a metaphor, they explain the differences between the various approaches: positivism is like an orchestra with clear-cut roles and expectations, anti-positivism is like a solo performer who does his or her own thing, and pragmatism is like a jazz ensemble where everyone has some freedom within a "loosely-defined framework" (p. 262). They concluded that pragmatic approaches to research can help the IS academic field to become more relevant and have an “increased interplay between research and practice” (p. 263). In this study, we utilize a pragmatic approach that recognizes the various goals, purposes, values, and complexities of HRD practice in seeking to understand the status of technology research in HRD. 


\section{Theoretical Perspective}

Instead of using a more divisive and exclusionary framework for classifying the articles examined in our study, we adapted the idea of metaperspectives for research and practice (McGuire, Garavan, O'Donnell, \& Watson, 2007). McGuire et al. present metaperspectives as a way of viewing HRD research and practice that allows for more appreciation of the diversity of perspectives that exist in this complex field. Their approach recognizes the realities of HRD practice and its "moving, complex, and contextual nature, resulting in the creation of a menu of intervention options and empowering innovative and critical thinking about its value, processes, and potential beneficiaries” (Garavan, O'Donnell, McGuire, \& Watson, 2007, p. 4). The metaperspectives framework recognizes the inherent strengths of the various approaches and does not create dualistic or divisive camps, as are often seen in categorizations of research and practice. For example, exploration of metaperspectives provides an alternative to the longstanding academic debate about whether HRD should emphasize learning or performance. In the conclusion to their issue of Advances in Developing Human Resources, McGuire, et al. (2007) propose four metaperspectives for HRD research and practice:

1. The community and/or societal metaperspective "recognizes the importance of HRD in advancing knowledge and skill among individuals across groups, countries, and economic regions” (McGuire et al., 2007, p. 133). Additionally, this metaperspective is seen through critical theory as it, "expose[s] the power relations among actors and mechanisms by which power and control are retained by management” (McGuire et al., 2007, p. 134).

2. The language metaperspective "recognizes the... 'linguistic turn'... [in HRD and that] language remains the principal method through which HRD can be developed” (McGuire et al., 2007, p. 132). "Social constructionism provides the theoretical foundations for the language metaperspective. ...HRD, as a construction, has been invented through language and discursive resources, particular ways of thinking about or framing social phenomena” (McGuire et al., 2007, p. 132).

3. The psychology metaperspective assists HRD in "help[ing] individuals understand themselves and their coworkers and enabl[ing] organizational personnel to deal more effectively with HRD issues and problems between employees” (McGuire et al., 2007, p. 134). Additionally, it explores mental processes and their effects on performance and behavior and concepts such as "the psychological contract, psychological empowerment, and psychological maturity” (McGuire et al., 2007, p. 134).

4. The systems metaperspective "recognizes the importance of achieving a best fit between the organization, HRD practice, and external environment” (McGuire et al., 2007, p. 132).

These metaperspectives do not line up neatly with other common research classification lenses (e.g., learning versus performance; positivism versus interpretivism versus critical perspectives). Instead, metaperspectives provide a classification scheme that can account for ontology, epistemology, and research occurring at various levels of analysis (McGuire et al., 2007). This theoretical perspective allows us to inventory and classify HRD technology research using categories that recognize the multifaceted purposes of HRD research and practice.

\section{Purpose of the Research}

The purpose of this article is to explore what is addressed by technology-related research in HRD publications and how it is addressed. This information will be useful to other researchers 
in determining future technology-related research needs. We analyze technology-related studies in HRD by examining the research in publications from the U.S.-based Academy of Human Resource Development (AHRD) and the U.K.-based University Forum for Human Resource Development (UFHRD). Publications from these organizations provide an indication of the status of technology-centered research in HRD. Although analyzing research from only two organizations and five publications is a limitation of the study, this research covers a lengthy period (seven years) and represents two of the main HRD research-oriented organizations in the U.S. and Europe. Other similar studies have sampled a comparable number of organizations/publications (e.g., Bierema \& Cseh, 2003; Orlikowski \& Baroudi, 1991).

In providing the quantity, topics, and approaches to HRD technology research, this study can help determine future research directions and needs. The following questions guided our study:

1. How much technology-related research is available in five HRD publications-Advances in Developing Human Resources (ADHR), Human Resource Development International (HRDI), Human Resource Development Quarterly (HRDQ), Human Resource Development Review (HRDR), and Proceedings of Academy of Human Resource Development Conference (Proceedings)?

This question provides the basic statistics regarding how much of this research is published in the field.

2. What are the technology-related papers addressing?

Through this question, we seek to understand the topics pursued, which will help identify gaps in the literature.

3. What fields/departments do the lead authors represent?

This question sought to determine whether HRD technology research is being generated from within academic departments of HRD or from other fields.

4. What methodological approaches are used?

Because of our initial assumption that certain publications (e.g., the Proceedings) published more technology research than the other publications, we wanted to understand whether there was a tendency for research in the Proceedings to be non-empirical (e.g., conceptual papers, theoretical research, literature reviews). This non-empirical research could have less chance of being published by some of the journals. Additionally, an inventory of methodological approaches can contribute to our understanding of future research needs.

5. What types of organizational settings are represented in the research? In order to help determine whether technology research reflected the realities of HRD practice, we sought to identify the settings of the research. HRD occurs in many settings and the organizational dynamics vary in different sectors.

6. What theoretical and practical orientations are represented in the research? We not only provide a basic inventory of the technology-related research, but also analyze each article according to the metaperspective(s) taken. Analyzing the theoretical and practical orientations of each paper will allow readers to understand the extent to which technology research in HRD represents a diversity of perspectives.

\section{Methods}

This research utilized a qualitative content analysis approach to answer the research questions. Patton (2002) defined content analysis as the process of "identifying, coding, and 
categorizing the primary patterns in the data” (p. 463). The following paragraphs describe a detailed account of this analysis.

\section{Assignment and Scope}

As authors of the paper, the four of us worked individually and as a group in completing this project. We gathered data by examining studies related to the broad theme of technology in the 2000-2006 issues of five HRD publications (except for the HRDR journal, which was started in 2002). In the initial identification, each of us examined specific conference proceedings and one set of journals for the years covered. By reading 1675 abstracts in the respective publications, we decided individually whether the different articles fell under the scope of the broad theme of technology. "Technology" included topics under the broad real of information technology, including enterprise-wide systems, learning technology and knowledge management. In addition to manually reading each abstract, we searched for articles using specific keywords in the database for each journal (i.e., technology, virtual, web-based, online, IT, knowledge management, distance education, e-learning, electronic communication, and blended learning). This automated search helped to ensure that no manuscripts were omitted. In the end, 169 manuscripts met these requirements.

\section{Inclusion and Exclusion of Articles}

We included only empirical and/or theory-based manuscripts. Consequently, articles such as book reviews, editorials, “soap boxes,” forums, invited reactions, interviews, innovative sessions, panel discussions, and pre-conference sessions were excluded because they were mainly opinion-based and/or did not contain detailed research findings. As a group, we examined studies ambiguously related to technology to determine the extent to which they addressed the technology theme. When differences occurred among group members, we discussed the papers until reaching a consensus. We categorized these ambiguous papers as "not included" if they had a minor relationship to technology (e.g., only one section of the article was dedicated to technology or technology was broadly included, but not the main focus of the article). In addition, we collaboratively discussed papers when one of us could not determine whether a particular article contained a sufficient amount of technology-related material.

\section{Thematic Categorization}

A major focus of this project was to thematically categorize the technology-related articles. Our initial individual reviews of the technology-related articles resulted in each researcher producing four separate lists of categories. Through an inductive content analysis (Patton, 2002), approximately 100 specific categories were developed. One researcher reconciled the four separate lists of categories from the rest of us, compiled them into one list of categories, and classified them into twelve initial categories. As described below, intercoder reliability was emphasized to ensure that the researchers' classifications were consistent since multiple individuals were engaged in the coding process (Miles \& Huberman, 1994). To refine the twelve categories, determine the accuracy of the researchers' coding, and to help ensure intercoder reliability, we collectively coded 56 technology-related articles. Through a series of meetings, the four of us compared individual categorization of these 56 articles and discussed how (a) these studies should be placed into specific categories; and, (b) how to reconcile different codings and classifications (Bierema \& Cseh, 2003). We refined the categories throughout this iterative process, which resulted in six categories. In addition, we completed the final categorization of 
the 56 articles, as a group, before each person performed a final categorization of his or her assigned articles. We used the following six categories and definitions in the final categorization:

Educational technology. Learning processes or tools that use information technology to facilitate formal learning in workplaces, higher education courses, and other settings (includes elearning, distance learning, and classroom technology).

Information technology (IT) workers. IT professionals who are impacted by HRD issues such as training, competency development, continuing professional education, skills certification, and organizational commitment in order to survive in the fast-paced IT field.

Knowledge management (KM). Tools that enable management and development of information and data that people need to be effective in their jobs. KM research is focused on technology-enabled management of knowledge and information (outside of formal, facilitated courses), using groupware, collaboration tools, data warehousing, data mining, tools for generating new knowledge, intranets, and electronic document management (Ardichvili, 2002).

Technological change, transfer, and implementation. The adoption of an innovation in a different setting from which it was developed, organizational issues surrounding the introduction of technologies and tools, and implementation of new technologies.

Virtual teams. Teams whose members share a common purpose and use technology to cross time zones, distance, and boundaries of organizations and/or cultures (Kim, 2004).

Other. Topics such as e-business, e-commerce, coaching through computer-mediated communication, transfer of training with e-learning, email, technology-related research methodology, and information technology (general scope). We concluded that these topics did not fit in the other five categories, given the working definitions listed above.

\section{Categorizing the Fields of Authors}

In order to determine if HRD technology researchers are employed in HRD departments, technology-centered departments (e.g., departments of instructional technology) or in more broadly focused departments, we located the home department of the lead author of each technology-related article. This data was found at the end of journal articles or in the AHRD directory included with the conference proceedings. When the department of the lead author was not listed, we performed Internet searches to find the lead author's affiliation at the time the paper was published. We found all but three of the lead authors' departments.

\section{Categorizing the Methodological Approaches to Research}

We examined the general methodology or approach used in each technology-related article. Approaches were categorized as empirical research, literature review, or theory development/conceptual. The first two categories were based on research conducted by Conn and Gitonga (2004), who defined empirical research as "reports on a research study that used data to draw conclusions" (p. 17) and literature reviews as a "summar[y of] a body of literature as a critique or to draw implications for practice” (p. 17). The third category, theory development/conceptual, described articles that (a) provided "a set of interrelated constructs, definitions, and propositions that present a rational view of phenomena by explaining or predicting relationships among those elements" (Camp, 2001, p. 11) or (b) provided an innovative examination of an issue in the field through a grounded research/theoretical approach which laid the groundwork for future research in the area (Decision Sciences Journal of Innovative Education, 2006). We added the third category because of HRD's emphasis on 
increasing the number of theory development pieces (e.g., see Hatcher, 2006; Lynham, 2000; Swanson \& Holton, 2001).

\section{Categorizing Organizational Settings}

For the technology-related empirical articles, we modified the organizational setting categories used by Conn and Gitonga (2004) to fit the types of articles identified for this study. The following categories were used: business, government/military, higher education courses, higher education professional development for faculty/staff, non-profit (also referred to as nongovernmental organizations), professional association/consortium, and other. "Higher education courses" included studies that examined for-credit courses, non-credit courses, or community outreach programs in colleges/universities. The "professional association/consortium" category emerged later, after finding that several studies examined groups that coordinate learning programs for multiple companies and organizations.

\section{Categorizing Theoretical and Practical Orientations}

A major focus of this project was to analyze each article according to the metaperspective(s) taken toward research and practice (McGuire et al., 2007). McGuire et al. proposed the four metaperspectives as a framework and we developed criteria for those metaperspectives through attributes mentioned in their article. Due to the complex and multiple foci of articles in these publications, we concluded that each article could utilize multiple metaperspectives. Three of us independently developed criteria lists for the four metaperspectives: community and/or societal, language, psychological, and systems. The four of us reconciled these separate lists of criteria into one list of criteria that would guide our analysis of the articles (see Table 1). We independently analyzed four articles (each representing apparently different perspectives) and collaboratively reconciled our different opinions on these articles. Next, we independently analyzed four additional articles, which we perceived to be difficult to categorize. Through debate and discussion, we reconciled our differences. We continued this process with three additional difficult-to-classify articles, at which point we easily came to a consensus on the classifications for each article. The remaining 158 articles were divided into two groups, with each of us pairing with another researcher to analyze each article. Again, the analyses were conducted independently, followed by a reconciliation of differences with the research partner. 
Table 1

Criteria for Categorizing Metaperspectives of HRD (adapted from McGuire et al., 2007)

Community and/or Societal - "recognizes the importance of HRD in advancing knowledge and skill among individuals across groups, countries, and economic regions” (p. 133). Additionally, this perspective is seen through critical theory as it, "expose[s] the power relations among actors and mechanisms by which power and control are retained by management” (p. 134).

1. Examines the role of HRD in advancing knowledge and skills to contribute to the community, national, or societal levels

2. Recognizes the potential of HRD to contribute to large-scale economic growth

3. Explores governmental influences, economies, educational systems and professional organizations

4. Examines the role of vocational, career, and technical education in contributing to the larger society

5. Exposes power relations

6. Recognizes the contested domains within HRD

7. Seeks to make organizations more just, equitable, and sustainable

Language - "recognizes the...'linguistic turn'...[in HRD and that] language remains the principal method through which HRD can be developed” (p. 132)

1. Explores discourse, symbols, stories, narratives, and the use of media in understanding HRD

2. Recognizes the social construction of knowledge through dialogue and social interaction (verbal and non-verbal)

3. Explores how social experiences are created and given meaning

Psychological - "assists HRD in "help[ing] individuals understand themselves and their coworkers and enabl[ing] organizational personnel to deal more effectively with HRD issues and problems between employees (p. 134). Additionally, it explores mental processes and their effects on performance and behavior and concepts such as "the psychological contract, psychological empowerment, and psychological maturity” (p. 134)

1. Seeks exploration of mental processes and their effects on performance and behavior, including concepts such as the psychological contract, psychological empowerment, and psychological maturity

2. Examines individual values and attitudes

3. Explores self-concept and identity construction

4. Explores the creation of a secure and supportive environment (e.g. manager support). 
Systems - "recognizes the importance of achieving a best fit between organization, HRD practice, and external environment” (p. 132)

1. Addresses input/output process.

2. Emphasizes the achievement of greater utility, productivity, and economic value.

3. Seeks to achieve fit between organization, HRD, and external environment (e.g., local circumstances, political environment, economic conditions, cultural aspects, globalization).

4. Recognizes situational characteristics, variability, or contingent nature of HRD practice

5. Responds to organizational needs and creates value

6. Recognizes the interdependence between individual, group, and organizational development

\section{Results and Discussion}

Volume of Technology-Related Research

The amount of technology-related research varied greatly among HRD publications. Over the seven years examined, 10.1 percent of HRD papers were considered technology-related. The total number and percentages of technology-related articles in each HRD publication are displayed in Table 2. Understandably, with the highest number of papers included in the Proceedings, this publication had the highest number of technology-related research papers. However, the Proceedings also had the highest percentage of papers addressing technology issues (13\%). Interestingly, the number of technology-related articles in the Proceedings increased over three times when comparing 2000 to 2006 (i.e., ten papers in 2000 and 38 papers in 2006). On the other hand, it was surprising to discover that $H R D Q$ only contained two technology-related research articles during these seven years (both in 2005). Of the four journals, ADHR published the most technology-related research (7.3\%). For the most part, technology-related research articles increased steadily from 2000 through 2006.

Table 2

Number of Technology-Related Articles in Five HRD Publications From 2000 through 2006 (\% of Total Articles Published)

\begin{tabular}{|c|c|c|c|c|c|c|}
\hline \multirow[b]{2}{*}{ Year } & \multicolumn{5}{|c|}{ Publication } & \multirow{2}{*}{$\begin{array}{c}\text { Total within } \\
\text { the year }\end{array}$} \\
\hline & ADHR & $H R D I$ & $H R D Q$ & $H R D R$ & Proceedings & \\
\hline 2000 & $0(0 \%)$ & $2(8 \%)$ & $0(0 \%)$ & $\mathrm{n} / \mathrm{a}$ & $10(7.3 \%)$ & 12 (5.8\%) \\
\hline 2001 & $0(0)$ & $1(3.9)$ & $0(0)$ & $\mathrm{n} / \mathrm{a}$ & $10(7.4)$ & $11(5.2)$ \\
\hline 2002 & $10(34.5)$ & $1(3.6)$ & $0(0)$ & $2(9.5)$ & $11(8.1)$ & $24(10.3)$ \\
\hline 2003 & $2(6.7)$ & $1(3.0)$ & $0(0)$ & $0(0)$ & $25(20)$ & $28(12.3)$ \\
\hline 2004 & $1(2.9)$ & $3(9.7)$ & $0(0)$ & $0(0)$ & 26 (16.9) & 30 (11.7) \\
\hline 2005 & $1(3.0)$ & $2(8.0)$ & $2(2)$ & $1(5)$ & 20 (11.9) & $26(9.8)$ \\
\hline 2006 & $2(5.9)$ & $3(10.3)$ & $0(0)$ & $0(0)$ & 33 (18.2) & 38 (13.7) \\
\hline $\begin{array}{l}\text { Total } \\
\text { within the } \\
\text { publication }\end{array}$ & $16(7.3 \%)$ & $13(6.6 \%)$ & $2(1.6 \%)$ & $3(3.1 \%)$ & 135 (13\%) & 169 (10.1\%) \\
\hline
\end{tabular}


Ten out of twelve technology-related articles were published in the Proceedings in 2000; the other two articles that year were published in HRDI (see Table 2). However, in 2002, the distribution changed substantially. Forty-four percent of the technology-related articles were published in the journals and 54\% were published in the Proceedings. The reason for the increase was an ADHR issue in 2002 that focused on Information and Learning Technologies in $H R D$. Generally, a very slight increase in technology-related articles was seen from 2002 through 2004, followed by a slight drop in 2005 and an increase in 2006.

The journals varied in their consistency of publishing technology-related research. HRDQ had only two articles primarily related to technology throughout these seven years. HRDR published three articles and $A D H R$ included technology articles during five of the seven years. Among the journals, HRDI was the most consistent publisher of technology-related research. Throughout the seven years examined, 13\% of all manuscripts in the Proceedings and 5\% of the journal articles addressed technology.

\section{Topics Addressed in Technology-Related Papers}

In looking at the publications separately, most technology-related articles from the Proceedings addressed educational technology (86), followed by virtual teams (18), and technology change, transfer, and implementation (10) (see Table 3). The other categories, IT workers, knowledge management, and other, had less than ten articles each. Among the journals, the most popular technology theme was educational technology. HRDI had nine articles addressing educational technology and $A D H R$ has six articles on that topic. HRDR had three technology-related articles - two were categorized under technological change, transfer, and implementation and the other dealt with educational technology. The articles in HRDQ dealt with educational technology and virtual teams. A summary of the number of articles under each of the topics addressed in technology-related papers is found in Table 3. Due to the prevalence of formal learning programs in the field of HRD, it is not surprising that a large portion (61\%) of the technology-related papers addressed educational technology, most of which were found in the Proceedings. However, the wide-variety of non-training topics in the journals' technologyrelated articles illustrate the growing emphasis placed on using technology for non-training interventions in HRD. As non-training interventions become increasingly prominent in HRD, additional emphasis beyond educational technology may become necessary.

Table 3

Number of Topics Addressed in Technology Research

\begin{tabular}{|c|c|c|c|c|c|c|}
\hline \multirow[b]{2}{*}{ Technology-related Topic } & \multicolumn{5}{|c|}{ Publication } & \multirow[b]{2}{*}{ Total } \\
\hline & $A D H R$ & HRDI & HRDQ & $H R D R$ & Proceedings & \\
\hline Educational Technology & 6 & 9 & 1 & 1 & 86 & 103 (61\%) \\
\hline Virtual Teams & 1 & 1 & 1 & 0 & 18 & $21(12 \%)$ \\
\hline $\begin{array}{l}\text { Technological Change, } \\
\text { Transfer, and }\end{array}$ & & & & & & \\
\hline Implementation & 4 & 0 & 0 & 2 & 10 & $16(9 \%)$ \\
\hline Knowledge Management & 3 & 2 & 0 & 0 & 5 & $10(6 \%)$ \\
\hline Other & 1 & 0 & 0 & 0 & 9 & $11(7 \%)$ \\
\hline $\begin{array}{l}\text { Information Technology } \\
\text { Workers }\end{array}$ & 2 & 1 & 0 & 0 & 7 & $8(5 \%)$ \\
\hline Total & 16 & 13 & 2 & 3 & 135 & $169(100 \%)$ \\
\hline
\end{tabular}


Fields/Departments of the Lead Authors

Naturally, most lead authors of technology-related articles came from HRD/Human Resource Education (44.4\%), with the other 55.6\% from a wide-variety of fields (see Table 4) such as academic departments of educational technology, adult/higher education, and business. Presumably, some of these individuals specialize in HRD, but are employed in other fields (e.g., an HRD specialist working in a school of business).

Table 4

Fields/Departments for Lead Authors of Technology-Related Research

\begin{tabular}{lcc}
\hline & Field/Department & Number \\
\hline Human Resource Development/Education & 75 & 44.4 \\
Adult/higher education & 15 & 8.9 \\
Educational Technology & 13 & 7.7 \\
Business & 12 & 7.1 \\
Technology & 8 & 4.7 \\
Private consulting (non-academic departments) & 6 & 3.6 \\
Educational Technology/HRD (non-academic departments) & 6 & 3.6 \\
Agriculture/Agriculture Education & 4 & 2.4 \\
Behavioral sciences & 4 & 2.4 \\
Leadership & 3 & 1.8 \\
Human Resource Management & 3 & 1.8 \\
University-based training provider (non-academic departments) & 2 & 1.2 \\
Technology research center & 1 & 0.6 \\
Miscellaneous & 9 & 5.3 \\
No information & 6 & 3.6 \\
\hline Total & 169 & 100 \\
\hline
\end{tabular}

Methodological Approaches to Research

As described earlier, articles were placed into one of three categories to depict the general methodology or approach to research: empirical, literature review, or theory development/conceptual. Out of 169 technology-related articles, 69.8\% of the articles were empirical studies, $14.8 \%$ were literature reviews, and $14.2 \%$ were theory development/conceptual pieces. A mere $1.2 \%$ of the technology-related articles were placed in a category called "other." This category included two articles that did not fit any of the three categories because (a) they provided informal case studies/scenarios from companies/programs/software to illustrate ideas and assertions; (b) no form of data collection was presented; and, (c) they did not contain a significant review of literature (i.e., included minimal citations or references to literature). Additionally, we found no reason to conclude that the Proceedings had an overrepresentation of literature reviews, since $75.5 \%$ of their technology articles were empirical.

As addressed in Table 5, when breaking down these approaches by the thematic categorization, the most frequently used methods shift considerably. Interestingly, regarding technological change, transfer, and implementation, more papers were published as theory 
development/conceptual studies (50\%) than as empirical research (25\%). Due to the broader scope of analysis often associated with this type of topic, fewer empirical settings may be available for this type of research. For the topics of IT workers, there was no research published as theory development/conceptual work; of eight articles, two were literature reviews, and six were empirical studies. If this topic continues to gain the attention of researchers, it is important to publish theory development/conceptual pieces, in order to build and test conceptual ideas in the area. It is notable that while papers addressing educational technology dominated the technology-related research during the seven years, the use of methodological approaches in those papers did not represent a diversity of approaches. In particular, additional theory development/conceptual pieces may be necessary.

Table 5

Number and Percentage of Methodological Approaches Used in Technology-Related Research

\begin{tabular}{|c|c|c|c|c|c|}
\hline & \multicolumn{4}{|c|}{ Methodological Approaches } & \multirow[t]{2}{*}{ Total } \\
\hline & $\begin{array}{l}\text { Literature } \\
\text { Review }\end{array}$ & $\begin{array}{l}\text { Empirical } \\
\text { Research }\end{array}$ & $\begin{array}{c}\text { Theory } \\
\text { Development } \\
\text { or Conceptual }\end{array}$ & Other & \\
\hline Knowledge & & & & & \\
\hline $\begin{array}{l}\text { Management } \\
\text { Technological }\end{array}$ & $2(20 \%)$ & $5(50 \%)$ & $2(20 \%)$ & $1(10 \%)$ & $10(100 \%)$ \\
\hline $\begin{array}{l}\text { Change, Transfer, } \\
\text { and Implementation } \\
\text { Educational }\end{array}$ & $4(25)$ & $4(25)$ & $8(50)$ & $0(0)$ & $16(100)$ \\
\hline Technology & $12(11.7)$ & $80(77.7)$ & $10(9.7)$ & $1(1)$ & $103(100)$ \\
\hline Virtual Teams & $2(9.5)$ & $16(76.2)$ & $3(14.3)$ & $0(0)$ & $21(100)$ \\
\hline IT workers & $2(25)$ & $6(75)$ & $0(0)$ & $0(0)$ & $8(100)$ \\
\hline Other & $3(27.3)$ & $7(63.6)$ & $1(9.1)$ & $0(0)$ & $11(100)$ \\
\hline Total & $25(14.8 \%)$ & $118(69.8 \%)$ & $24(14.2 \%)$ & $2(1.2 \%)$ & $169(100 \%)$ \\
\hline
\end{tabular}

\section{Organizational Settings}

As seen in Table 6, many of the papers (34.3\%) dealt with higher education courses. Higher education courses were used for technology-related research published in the Proceedings while none of the HRD journals published research from settings related to these courses. Business organizations were also well represented, with $33.7 \%$ of the papers addressing business settings. Organization settings represented less frequently included non-profit and government/military organizations. 
Table 6

Number of Organizational Settings Represented in Technology-Related Research

\begin{tabular}{|c|c|c|c|c|c|c|}
\hline \multirow[b]{2}{*}{ Organizational setting } & \multicolumn{5}{|c|}{ Publication } & \multirow[b]{2}{*}{ Total } \\
\hline & $A D H R$ & $H R D I$ & $H R D Q$ & HRDR & Proceedings & \\
\hline Higher Education Courses & 0 & 0 & 0 & 0 & 58 & 58 (34.3\%) \\
\hline Business & 9 & 5 & 1 & 1 & 41 & $57(33.7 \%)$ \\
\hline Professional & & & & & & \\
\hline Associations/Consortiums & 0 & 2 & 0 & 0 & 5 & $7(4.1 \%)$ \\
\hline Government/Military & 0 & 2 & 0 & 0 & 4 & $6(3.6 \%)$ \\
\hline $\begin{array}{l}\text { Higher Education } \\
\text { professional development }\end{array}$ & & & & & & \\
\hline for faculty/staff & 0 & 1 & 1 & 0 & 2 & $4(2.4 \%)$ \\
\hline Non-Profit Organizations & 0 & 1 & 0 & 0 & 3 & $4(2.4 \%)$ \\
\hline Other & 0 & 2 & 0 & 0 & 8 & $10(5.9 \%)$ \\
\hline No organizational setting & 7 & 0 & 0 & 2 & 14 & $23(13.6 \%)$ \\
\hline
\end{tabular}

Theoretical and Practical Orientations

Table 7 illustrates the overall diversity of metaperspectives represented across technology research. Although the publications varied somewhat, most of them reflected a dominant systems (67.4\%) metaperspective, followed by psychological (52.1\%), language (18.3\%), and community and/or societal (15.4\%). This general order of distribution held true for articles addressing educational technology and virtual teams. However, research on technological change, transfer, and implementation, as well as IT workers were the exception, which had more articles utilizing the community and/or societal metaperspective than the language metaperspective. Knowledge management also had more articles using the language metaperspective than the psychological metaperspective (see Table 7). Dominance of the systems metaperspective is consistent with findings showing that a large percentage of technology-related research was done in businesses settings. In this setting, systems thinking (i.e., seeing unitary wholes and complex processes of change) is a prevalent goal in the achievement of organizational goals and objectives (Cummings \& Worley, 2005).

Table 7

Number of Metaperspectives Represented in the Different Topics of Technology-related Research

Technology-related Topic

\section{Technological}

Change,

Educational Virtual Transfer, and Knowledge IT

Metaperspective Technology Teams Implementation Management Workers Other Total

\begin{tabular}{llllllll}
\hline Systems & 64 & 16 & 14 & 9 & 6 & 5 & $(67.4 \%)$ \\
$\begin{array}{l}\text { Psychological } \\
\text { Language }\end{array}$ & 62 & 10 & 5 & 2 & 4 & 5 & $88(52.1)$ \\
$\begin{array}{l}\text { Community } \\
\text { and/or Societal }\end{array}$ & 12 & 5 & 3 & 4 & 1 & 4 & $31(18.3)$ \\
\hline
\end{tabular}


Studies taking a psychological perspective have historically had more focus on narrow variables, due to the dominant approach taken in that discipline. HRDI and ADHR reflected a lower psychological metaperspective in comparison with the other publications conceivably because of HRDI's European influence and $A D H R$ 's practitioner focus. The European influence can lead to a more critical approach to the study of HRD, with left wing-ideology and the study of dysfunctional organizational processes being more common (Keegan \& Boselie, 2006; Wasti, Poell, \& Cakar, in press). “ADHR's practitioner focus reflects a more strategic approach, which is a characteristic of the system metaperspective. These results contradict the claim that technology research is almost exclusively focused on narrow variables within isolated organizations, since $15.4 \%$ of the papers were classified as using a community and/or societal metaperspective, which inherently takes broader perspectives. The majority of the papers were classified in the "systems" metaperspective (67.4\%), which further suggests that HRD technology research is not merely focusing on narrow variables. As described in the opening sections, technology research has been criticized for a narrow focus on specific variables. Our finding seems to refute that claim, within HRD research. As reflected in Table 8, the publication with the most equal distribution of metaperspectives was the Proceedings. In other words, the Proceedings included the most papers from a variety of metaperspectives.

Table 8

Percentage of Metaperspectives Represented in Five HRD Publications from 2000 through 2006 (each article could represent multiple categories, $N=169$ )

\begin{tabular}{lcccccc} 
& \multicolumn{5}{c}{ Publication } & Total \\
\cline { 2 - 6 } Metaperspective & ADHR & HRDI & HRDQ & HRDR & Proceedings & 67.5 \\
\hline Systems & 87.5 & 76.9 & 50.0 & 100 & 63.7 & 52.1 \\
Psychological & 18.8 & 38.5 & 50.0 & 100 & 56.3 & 18.3 \\
Language & 6.3 & 15.4 & 0 & 33.3 & 20.0 & 15.4 \\
$\begin{array}{l}\text { Community and/or } \\
\text { Societal }\end{array}$ & 18.8 & 7.7 & 0 & 33.3 & 17.0 & \\
\hline
\end{tabular}

Since each article could represent multiple metaperspectives, Figure 1 depicts the percentage of articles representing one, two, or three metaperspectives. It shows that the percentage of articles utilizing multiple metaperspectives fluctuated over the seven-year period. In the last years we examined, a trend occurred with greater numbers of articles utilizing multiple metaperspectives. 
Figure 1. Percentage of Articles Representing Multiple Metaperspectives from 2000 through 2006

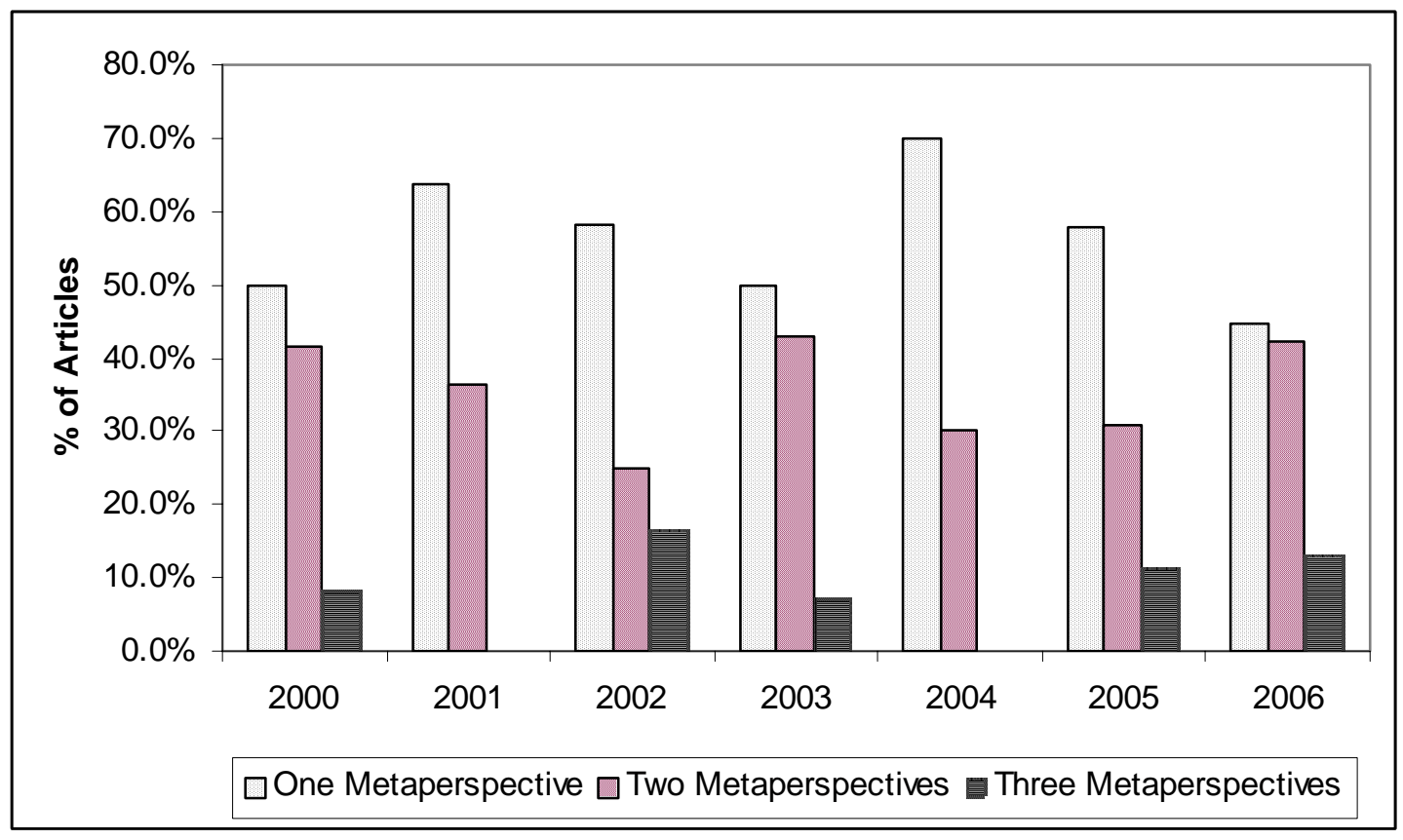

Regarding topics addressed in the articles, the educational technology articles had more focuses on a single metaperspective (59.2\%); while 34\% used two metaperspectives and 6.8\% used three metaperspectives. This distribution is similar to the knowledge management. On the other hand, articles addressing IT workers had a more equal distribution of articles using one (37.5\%), two (37.5\%), and three metaperspectives (25\%). Although most articles about technological change, transfer, and implementation were published using a single metaperspective (56\%), there were more articles utilizing three metaperspectives (25\%) than articles using two metaperspectives (18.8\%). Interestingly, more articles about virtual teams were published using two metaperspectives (57.1\%) than one metaperspective (38.1\%). These findings indicate that educational technology and knowledge management research were more focused on a single orientation toward research and practice, when compared with the other types of technology research. The other types of research seem to have more diverse and divergent orientations.

\section{Conclusions}

The purpose of this paper is to explore what and how technology is examined in HRD. We seek to contribute new knowledge to the field by assisting in the identification of future research needs related to technology. In concluding the article, we address the limitations of the research, our recommendations, and implications for HRD research and practice.

\section{Limitations}

Our analysis of HRD technology research has limitations and imperfections. Most obvious, we limited our analysis to studies within the publications of two professional organizations. We recognize that other respectable HRD publications exist. However, we 
concluded that a bounded study of HRD research within these two cooperating organizations was the best and most practical approach for us to take. We sought to assist in the identification of future needs for technology-related research; however, we recognize that the study merely looks back at past research. Other processes and studies need to be undertaken to fully identify future research needs.

The four of us each bring our own unique perspectives to this field. Although we do bring a great deal of diversity in terms of our cultural backgrounds (Kenyan, Lebanese, North American, and Taiwanese) and an even gender ratio (two females and two males), our analysis of the research is inevitably shaped by our individual and collective experiences and histories. These backgrounds undoubtedly influenced the way we approached this project and interpreted the papers that we analyzed. Two of us focus on technology for a great deal of our own research and the other two of us focus primarily on other aspects of HRD. Within these areas, we each have our own specific areas of focus, which we often conclude are deserving of more coverage in the HRD literature. Additionally, we bring our own perspectives about broad issues of HRD and research. Throughout this project, we debated over the ultimate aims and purposes of research in general, the interaction between research and practice, and the most appropriate goals for HRD. This debate and diversity ultimately resulted in a paper that represents multiple viewpoints and aims to analyze HRD research without being divisive.

\section{Implications for Research and Practice}

In this closing section, we address our research questions and draw conclusions about how this study provides answers and future directions for HRD research. Technology is a major force influencing organizations today and permeates many aspects of HRD practice. In considering the research question about how much technology research is available, we are reluctant to say there is a need for inclusion of more technology-related research in HRD publications since many researchers claim the need for additional research in their particular area of study. We also acknowledge that although technology is the focus in this article, it is only one area of study in the broad field of HRD. In other words, we understand that technology will not be the primary focus of the HRD field. In our analysis, a high percentage of the research found in the Proceedings addressed technology. ADHR and HRDI contained notable percentages of technology articles while technology-related research was irregular or nearly non-existent in $H R D Q$ and $H R D R$ (see Table 2). This pattern is understandable since each publication pursues different missions. Nonetheless, with the widespread influence of technology in HRD research and practice, we contend that more technology research is needed in $H R D Q$ and $H R D R$.

Additionally, other technology-related topics need to be explored. Educational technology in higher education courses took center stage in the technology research of the Proceedings (see Table 6). We conclude that HRD professionals and researchers should conduct more organization-focused technology research in areas such as technology transfer, virtual teams, knowledge management systems, and other unidentified technology areas affecting HRD practice. Organizations spend billions of dollars annually on new technologies that restructure the daily work of employees. With these changes, there is a need for HRD researchers to examine how these changes affect workplaces and HRD's role in facilitating these changes.

The presence of HRD research conducted by authors from other fields shows that these HRD publications are seen as an outlet for researchers outside of HRD departments since 56\% of the lead authors were not affiliated with HRD departments. The remaining $44 \%$ of the authors 
are employed within HRD departments, showing that researchers in these departments are also pursuing technology-related research.

Different research methods are also needed in technology-related research. From our findings, most research was done empirically (69\%). As an emergent and constantly changing field, technology needs to be explored further through theory development/conceptual pieces. HRD researchers should consider collaborating with practitioners to develop new theories in the field of technology. Additionally, we found that $75.5 \%$ of technology research in the Proceedings was empirical, which refutes our initial speculation that technology research was not making it to the journals due to an overemphasis on reviews of literature. There is a critical need for theoretical and conceptual studies of educational technology, so that the research findings can be consolidated and the development of this area can evolve.

A broader spectrum of organizational settings needs to be examined in HRD technology research. Although businesses were well represented, other organization types were largely ignored in these papers, particularly non-profit and government/military organizations. As mentioned earlier, higher education courses seem to be over-represented in the Proceedings. Although we recognize that HRD is broad and difficult to define (e.g., Lee, 2001; McLean \& McLean, 2001), this finding was surprising since HRD is largely seen as a field dedicated to individual and organizational development within the context of workplaces and other organizations (e.g., Academy of Human Resource Development, 2005). A primary reason for the large percentage of papers using higher education courses as a setting might be that academic researchers have easy access to these courses for empirical studies on educational technology. However, higher education courses have different dynamics and characteristics than learning that occurs in workplaces and other organizational settings. HRD researchers need to seek out more opportunities to conduct technology research in workplaces and other organizational settings. This research can be conducted by practitioners or in partnerships between practitioners and researchers (Hamlin, 2006; Tyler, 2006).

An overall concern from this study is that technology-related papers in the Proceedings are not making it to the journals. This problem could be attributed to several possible reasons. First, technology-related research may not be submitted to the HRD journals, in favor of more technology-focused journals. Another reason might be some type of bias against technologyrelated research on the part of the journal reviewers. Thirdly, technology-related papers that are submitted to the journals may be considered inadequate or lack the quality needed for publication in these journals. Perhaps this happens if newer, less experienced scholars write about technology more often than senior researchers. A fourth reason may be the lack of suitability of research submitted to the journals due to the dominant focus on higher education courses. A last possible reason is that since technology research is rarely published in these journals, researchers may conclude they should not submit technology-related articles to the journals. Whatever the reasons, it is troubling to discover the near absence of any articles focusing on technology in AHRD's oldest journal, $H R D Q$. HRD researchers should engage in dialogue with editors and reviewers to discuss ways that more technology-related articles can be published in HRD journals since the use of technology is a growing emphasis in HRD practice. Moreover, HRD technology researchers interested in publishing in HRDQ or HRDR should carefully consider the respective missions of those journals in order to develop manuscripts that are suitable both topically and methodologically for those audiences.

From our perspective, a surprising amount of diversity was present when examining the papers' theoretical and practical orientations. Contrary to past studies that found HRD research 
or technology research to be overly narrow (Bierema \& Cseh, 2003; Orlikowski \& Baroudi, 1991; Walsham, 1995), we found evidence to suggest that researchers are beginning to adopt broader perspectives. As further evidence, we found that increasing numbers of articles utilized multiple metaperspectives in the latter years of our analysis. Not surprisingly, the Proceedings, which is often seen as more open to new and different perspectives (Bierema \& Cseh, 2003) had the largest representation of multiple metaperspectives, when compared to the other publications.

In our literature review, we expressed a desire to avoid railing against certain perspectives and repeating the "paradigm wars" debate seen in other fields. Instead, we advocated the pragmatist goal of using methodologies that "work," while considering value questions of "usefulness" (Goles \& Hirschheim, 2000). Although we remain committed to that goal, it is worth considering whether technology researchers could find additional use for the two underutilized metaperspectives. We conclude that researchers should increase their consideration for using community and/or societal perspectives. Taulbert (2002) reminds us of the risks associated with technology implementation and that we must continue to acknowledge the importance of community and personal interaction as our workplaces become more automated. Likewise, community and/or societal issues like gender, race, nationality, class, and education influence our experience with technology (Benson, 2004; Conceiçäo, 2002). These issues must be examined by HRD in order to ensure that technology is not a barrier to full participation in workplaces and organizations.

According to Garrison and Anderson (2003), issues of language and dialogue are of central importance in effective e-learning programs. The language metaperspective was represented in $18.3 \%$ of the articles reviewed. Additionally, as technology research begins to examine the "why" questions rather just "how," language becomes more central (e.g., in postmodern and poststructuralist perspectives) (Hlynka, 2004; Lennie, Hatcher, \& Morgan, 2003). Overall, these language perspectives should continue to be developed.

Wasti, Poell, and Çakar (in press) conducted an analysis of HRD literature to reveal underlying orientations and methodological approaches. While their work focuses on the overarching orientations that may be used to define the HRD field (learning vs. performance; practice vs. empiricist), our research takes on a different set of orientations to deepen our understanding of the lenses used in HRD technology-related research. Thus, through this inventory and analysis of technology-related HRD research, we have contributed to the field by providing a foundation from which technology researchers can consider future directions in their research. Additionally, we have used the metaperspectives lens as a non-divisive tool for analyzing the orientations toward research and practice in HRD. With the continuing growth of technology-related research and this article providing a point of consideration for future research needs, we remain hopeful that others whose practice and research deals with technology in workplaces and organizations will come to know about these publications. Collaboration with practitioners will help to increase the relevance and appropriateness of technology-related research in HRD. A more specific focus on the use of technology in workplaces and organizations will help these HRD publications become known as an appropriate source and outlet for HRD technology research. We conclude that this increased focus will bring about a wider variety of organizational settings, research methods, and metaperspectives represented in HRD technology research. 


\section{References}

Academy of Human Resource Development. (2005). Constitution of The Academy of Human Resource Development. Retrieved August 28, 2005, from http://www.ahrd.org/ABOUT/bylaws/AHRD_Constitution_March_2005.pdf

Alavi, M., \& Carlson, P. (1992). A review of MIS research and disciplinary development. Journal of Management Information Systems, 8(4), 45-62.

Ardichvili, A. (2002). Knowledge management, human resource development, and Internet technology. Advances in Developing Human Resources, 4(4), 451-463.

Benson, A. D. (2004). Distance education: Ready and willing to serve the underserved? The Quarterly Review of Distance Education, 5(1), 51-57.

Benson, A. D., Johnson, S. D., \& Kuchinke, K. P. (2002). The use of technology in the digital workplace: A framework for human resource development. Advances in Developing Human Resources, 4(4), 392-404.

Bierema, L. L., \& Cseh, M. (2003). Evaluating AHRD research using a feminist research framework. Human Resource Development Quarterly, 14(1), 5-26.

Bredo, E., \& Feinberg, W. (1982). Knowledge and values in social and educational research. Philadelphia: Temple University Press.

Burrell, G., \& Morgan, G. (1979). Sociological paradigms and organisational analysis: Elements of the sociology of corporate life. London: Heinemann.

Camp, W. G. (2001). Formulating and evaluating theoretical frameworks for career and technical education research. Journal of Vocational Education Research, 26(1), 4-25.

Conceiçäo, S. (2002). The sociocultural implications of learning and teaching in cyberspace. New Directions for Adult and Continuing Education, 96, 37-45.

Conn, C. A., \& Gitonga, J. (2004). The status of training and performance research in the AECT journals. TechTrends, 48(2), 16-20, 78.

Cummings, T. G., \& Worley, C. G. (2005). Organization development and change (8th ed.). Mason, $\mathrm{OH}$ : Thomson/South-Western.

Decision Sciences Journal of Innovative Education. (2006). Author Guidelines. Retrieved July 15, 2007, from http://www.blackwellpublishing.com/submit.asp?ref=1540-4595

Fenwick, T. J. (2004). Toward a critical HRD in theory and practice. Adult Education Quarterly, 54(3), 193-209.

Fenwick, T. J. (2005). Conceptions of critical HRD: Dilemmas for theory and practice. Human Resource Development International, 8(2), 225-238.

Freeman, M., Kim, E., Kim, E. A., Valenziano, L., Gitonga, J., \& Benson, A. (2006). Workplace learning and performance improvement in AHRD journals. In F. M. Nafukho (Ed.), Academy of Human Resource Development Conference Proceedings (pp. 75-81). Bowling Green, OH: AHRD.

Garavan, T. N., O'Donnell, D., McGuire, D., \& Watson, S. (2007). Exploring perspectives on human resource development: An introduction. Advances in Developing Human Resources, 9(1), 3-10.

Garrison, D. R., \& Anderson, T. (2003). E-learning in the 21st century: A framework for research and practice. London: RoutledgeFalmer.

Gedro, J. (2007). Conducting research on LGBT issues: Leading the field all over again! Human Resource Development Quarterly, 18(2), 153-158. 
Githens, R. P. (2007). Critical action research in human resource development. In F. M. Nafukho (Ed.), Academy of Human Resource Development Conference Proceedings (pp. 481488). Bowling Green, OH: AHRD.

Goles, T., \& Hirschheim, R. (2000). The paradigm is dead, the paradigm is dead...long live the paradigm: The legacy of Burrell and Morgan. Omega, 28(3), 249-268.

Hamlin, R. G. (2006). Evidence-based practice through HRD professional partnership research. In F. M. Nafukho (Ed.), Academy of Human Resource Development Conference Proceedings (pp. 1073-1080). Bowling Green, OH: AHRD.

Hatcher, T. (2006). An editor's challenge to human resource development. Human Resource Development Quarterly, 17(1), 1-4.

Hlynka, D. (2004). Postmodernism in educational technology: update: 1996-present. In D. H. Jonassen (Ed.), Handbook of research on educational communications and technology (2nd ed., pp. 243-246). Mahwah, N.J.: Lawrence Erlbaum.

Information Technology Association of America. (n.d.). Information technology definition aggregation. Retrieved February 1, 2008, from http://www.itaa.org/es/docs/Information\%20Technology\%20Definitions.pdf

Jacobs, R. L. (2006). Perspectives on adult education, human resource development, and the emergence of workforce development. New Horizons in Adult Education and Human Resource Development, 20(1), 21-31.

Keegan, A., \& Boselie, P. (2006). The lack of impact of dissensus inspired analysis on developments in the field of human resource management. Journal of Management Studies, 43(7), 1491-1511.

Kim, S. (2004). Team development of virtual teams. In T. M. Egan (Ed.), Academy of Human Resource Development Conference Proceedings (pp. 1018-1022). Bowling Green, OH: AHRD.Kuchinke, K. P. (2004). Theorizing and practicing HRD: Extending the dialogue over the roles of scholarship and practice in the field. Human Resource Development International, 7(4), 535-539.

Lee, M. (2001). A refusal to define HRD. Human Resource Development International, 4(3), 327-341.

Lennie, J., Hatcher, C., \& Morgan, W. (2003). Feminist discourses of (dis)empowerment in an action research project involving rural women and communication technologies. Action Research, 1(1), 57-80.

Lynham, S. A. (2000). Theory building in the human resource development profession. Human Resource Development Quarterly, 11(2), 159-178.

McGuire, D., Garavan, T., O'Donnell, D., \& Watson, S. (2007). Metaperspectives and HRD: Lessons for research and practice. Advances in Developing Human Resources, 9(1), 120139.

McLean, G., \& McLean, L. (2001). If we can't define HRD in one country, how can we define it in an international context? Human Resource Development International, 4(3), 313-326.

Miles, M. B., \& Huberman, A. M. (1994). Qualitative data analysis: An expanded sourcebook (2nd ed.). Thousand Oaks, CA: Sage.

Nardi, B., \& O'Day, V. (1999). Information ecologies: Using technology with heart. First Monday, 4(5).

Orlikowski, W. J., \& Baroudi, J. J. (1991). Studying information technology in organizations: Research approaches and assumptions. Information Systems Research, 2(1), 1-28. 
Patton, M. Q. (2002). Qualitative research and evaluation methods (3rd ed.). Thousand Oaks, CA: Sage.

Reffell, P., \& Whitworth, A. (2002). Information fluency: Critically examining IT education. New Library World, 103(11/12), 427-435.

Rocco, T. S., McCarley, H., Ianinska, S., Plakhotnik, M. S., Bernier, J., \& Gonzalez, C. (2005). An examination of qualitative empirical studies at the AHRD from 1999-2003: Method and integrity. In M. L. Morris (Ed.), Academy of Human Resource Development Conference Proceedings (pp. 513-520). Bowling Green, OH: AHRD.

Smith, P. J. (2006). Technical rationality and professional artistry in HRD practice. Human Resource Development International, 9(2), 271-281.

Storberg-Walker, J. (2007). Creating alternative social capital theories: Disciplined imagination from four perspectives. In F. M. Nafukho (Ed.), Academy of Human Resource Development Conference Proceedings (pp. 39-46). Bowling Green, OH: AHRD.

Sugrue, B., \& Rivera, R. J. (2005). ASTD 2005 State of the Industry Report. Alexandria, VA: American Society for Training and Development.

Swanson, R. A., \& Holton, E. F., III. (2001). Foundations of human resource development (1st ed.). San Francisco: Berrett-Koehler.

Taulbert, C. L. (2002). Touch and technology: The look of sensory contact in the new millennium. In C. Sleezer, T. L. Wentling \& R. L. Cude (Eds.), Human resource development and information technology: Making global connections (pp. 245-253). Boston: Kluwer Academic Publishers.

Tyler, J. A. (2006). Re-searching research models: What is emergent, elastic, and nonlinear all over? Human Resource Development Review, 5(4), 494-505.

Valentin, C. (2006). Researching human resource development: Emergence of a critical approach to HRD enquiry. International Journal of Training \& Development, 10(1), 17-29.

Walsham, G. (1995). The emergence of interpretivism in IS research. Information Systems Research, 6(4), 376-394.

Wasti, S. A., Poell, R. F., \& Cakar, N. D. (in press). Oceans and notions apart? An analysis of the U.S. and European human resource development literature. International Journal of Human Resource Management. 